\title{
Role of anuria in the relationship between indoxyl sulfate and anemia in peritoneal dialysis patients
}

\author{
This article was published in the following Dove Press journal: \\ Therapeutics and Clinical Risk Management \\ 28 November 2016 \\ Number of times this article has been viewed
}

\author{
Jeng-Yi Huang ${ }^{1,2}$ \\ Ching-Wei Hsu',2 \\ Chih-Wei Yang ${ }^{1,2}$ \\ Cheng-Chieh Hung ${ }^{1,2}$ \\ Wen-Hung Huang ${ }^{1,2}$ \\ 'Kidney Research Center, Department \\ of Nephrology, Chang Gung Memorial \\ Hospital, Linkou Branch, Taipei, ${ }^{2}$ Chang \\ Gung University School of Medicine, \\ Taoyuan, Taiwan
}

Correspondence: Wen-Hung Huang Department of Nephrology, Chang Gung Memorial Hospital, No 5, Fu Hsing Street, Kuei-Shan, Taoyuan 333, Taiwan

Tel +886 3328 I200, ext 2024

Fax +88633282173

Email williammedia@gmail.com

\begin{abstract}
Background: Experimental evidence suggests that indoxyl sulfate (IS) is associated with chronic kidney disease-related anemia. However, clinical studies are limited, and few have explored the potential confounding effect of anuria. This study, thus, evaluated the association between IS and anemia in both non-anuric and anuric peritoneal dialysis (PD) patients.
\end{abstract}

Methods: This cross-sectional and observational study included 165 chronic PD patients aged 19-84 years. Their serum IS levels in total and free forms were measured by ultra performance liquid chromatography. Correlations between serum IS and hemoglobin ( $\mathrm{Hb})$ were performed in both non-anuric and anuric groups.

Results: Among the study subjects, 90 were non-anuric and 75 were anuric. As a whole, there was no correlation between IS and $\mathrm{Hb}$. Nonetheless, subsequent analysis of the non-anuric patients showed that $\mathrm{Hb}$ is negatively correlated with IS levels $\left(r_{s}=-0.405, P<0.001\right.$ for total form and $r_{s}=-0.296, P=0.005$ for free form). Factors that significantly affected Hb levels in the stepwise multiple regression analysis include total IS and iron saturation. In contrast for anuric patients, serum ferritin, albumin, iron saturation, use of angiotensin-converting enzyme inhibitor/angiotensin II receptor blocker, but not serum IS, were predictors for anemia in the multiple regression model.

Conclusions: Serum IS is associated with an increased severity of anemia in non-anuric PD patients and not in anuric ones, indicating anuria could be a confounding factor in such association.

Keywords: indoxyl sulfate, anemia, peritoneal dialysis, anuria

\section{Introduction}

Anemia is both highly prevalent in patients with chronic kidney disease (CKD) and an independent risk factor for morbidity and mortality in end-stage renal disease. ${ }^{1}$ Causes of uremic anemia are multifactorial, including erythropoietin deficiency, chronic inflammation, nutritional deficiency, hyperparathyroidism, iron deficiency, blood loss, aluminum intoxication, and vitamin D deficiency. ${ }^{2,3}$ The introduction of erythropoiesis-stimulating agents (ESAs) and maneuvers to correct recognized risk factors have effectively improved anemia. Still, the treatment of uremic anemia remains a challenging task given that high-dose ESA therapy is associated with increased cardiovascular risks. ${ }^{4-6}$

The existence of specific inhibitory uremic retention solutes for erythropoiesis has long been considered. However, increased clearance of water-soluble uremic retention solutes by using high-flux dialysis or on-line hemodiafiltration was unable to correct anemia in a better manner. ${ }^{7,8}$ Recently, the role of indoxyl sulfate (IS), a prototype of protein-bound retention solute, in CKD-related anemia has attracted special attention. It has been demonstrated in some in vitro studies that IS could suppress erythroid colony 
formation depending on its concentration ${ }^{9}$ and dysregulate oxygen metabolism in tubular cells and desensitize oxygensensing mechanism, leading to inadequate erythropoietin production. ${ }^{10}$ Furthermore, IS was shown to trigger in vitro suicidal erythrocyte death by enhancing extracellular calcium entry. ${ }^{11}$ Still, its clinical role in CKD-related anemia remains uncertain. One study in patients with diabetic nephropathy revealed a negative correlation between serum IS levels and hematocrit. ${ }^{12}$ Alternatively, using AST-120, an oral absorbent to reduce IS burden in CKD patients, has yielded inconsistent results. ${ }^{13,14}$

It is debatable whether serum IS level could reliably reflect the body burden in CKD patients. Eloot et al found a trend of elevation in serum total IS level following the progression of CKD from stages II to $\mathrm{V} .{ }^{15}$ By contrast, two studies showed only mild to modest increase in serum IS level in peritoneal dialysis (PD) patients without residual renal function when compared with those with residual renal function. ${ }^{16,17}$ Viaene et al, however, demonstrated a remarkable increase in incident PD patients in parallel with loss of residual renal function. ${ }^{18}$ As anuria might also be linked to the development of inflammation, malnutrition, hyperparathyroidism, and accumulation of diverse uremic retention solutes, we hypothesized that these factors together may interfere with the role of IS in CKD-associated anemia. For this purpose, we conducted a cross-sectional study to assess the connection between serum IS and anemia in chronic PD patients and evaluate the impact of anuria on this association.

\section{Materials and methods Study design}

End-stage renal disease patients who were older than 18 years and had undergone regular $\mathrm{PD}$ for $>3$ months were eligible for the study. We excluded patients with the following conditions: systemic lupus erythematosus and other collagen diseases, malignancy, active infection, recent gastrointestinal bleeding, autosomal-dominant polycystic kidney disease, and current treatment with immunosuppressive agents. Participants in this study received annual routine examinations including tests for complete blood count, sequential multiple analysis test, serum transferrin saturation, ferritin, intact parathyroid hormone (iPTH), and high-sensitivity C-reactive protein (hsCRP). Serum hsCRP was quantified by nephelometry (Sekisui, Tokyo, Japan), serum albumin levels by the bromocresol green method (Medipro, Yilan, Taiwan), and iPTH by the chemiluminescence method (Siemens, Tarrytown, NY, USA). Twenty-four-hour urine and effluent samples were collected to evaluate the renal and peritoneal clearance of creatinine and urea.

ESA was administered according to the guidelines issued by the National Health Insurance, Taiwan. The hematocrit target was between $33 \%$ and $36 \%$. The ESA dose was reduced when hematocrit approached the target, and ESA was discontinued once the hematocrit was $>36 \%$. The maximal monthly ESA dose was restricted to 20,000 U of recombinant human erythropoietin or the equivalent of $100 \mu \mathrm{g}$ darbepoetin.

The key variables of interest for this study were hemoglobin $(\mathrm{Hb})$ and IS. In addition, we collected the patients' clinical data such as their age, gender, causes of end-stage renal disease, PD vintage, laboratory tests, and medications, such as ESA, angiotensin-converting enzyme inhibitor (ACEI), and angiotensin II receptor blocker (ARB) by reviewing their medical records. Patients with a daily urine output of $<50 \mathrm{~mL}$ were arbitrarily considered anuric.

This clinical study was conducted in accordance with the Declaration of Helsinki and was approved by the Medical Ethics Committee of Chang Gung Memorial Hospital. Written informed consent was obtained from all participants.

\section{IS measurements}

Measurements of serum IS concentrations were carried out on the Waters Acquity UPLC system (Milford, MA, USA), which included a binary solvent manager, sampler manager, and column compartment. The UPLC assay was performed at $30^{\circ} \mathrm{C}$ on an Acquity UPLC BEH phenyl column of $2.1 \times 100 \mathrm{~mm}$ with a VanGuard phenyl column $(2.1 \times 5 \mathrm{~mm})$. IS measurements were performed with the Waters Acquity UPLC photo diode array detector with UV detection at $280 \mathrm{~nm}$. Buffer flow was set at $0.4 \mathrm{~mL} / \mathrm{min}$ for $5 \mathrm{~min}$ using $10 \mathrm{mM} \mathrm{NH}_{4} \mathrm{H}_{2} \mathrm{PO}_{4}(\mathrm{pH} 4.0)(\mathrm{A})$ and acetonitrile (B) with a gradient from $82.5 \% \mathrm{~A} / 17.5 \% \mathrm{~B}$ to $55 \% \mathrm{~A} / 45 \% \mathrm{~B}$. The sample volume injected was $2 \mu \mathrm{L}$. We measured the free concentrations of IS in serum ultrafiltrates obtained using Microcon YM-30 separators (Millipore, Billerica, MA, USA) with a molecular weight cutoff of $30 \mathrm{kDa}$. The assay detection limit was $0.25 \mathrm{mg} / \mathrm{L}$, and recoveries were in the order of $99.88 \%$.

\section{Statistical analyses}

Descriptive statistics are presented as the mean with standard deviation (SD) or the median with its interquartile range depending on the underlying distribution. Continuous variables were evaluated for the assumed normal distribution using the Kolmogorov-Smirnov test. Logarithmic transformation was 
applied to the data to approximate the normal distribution. We compared the clinical characteristics and laboratory data between anuric and non-anuric patients with the $\chi^{2}$ test or Fisher's exact test for frequencies or proportions. We used the Student's $t$-test for normally distributed continuous variables and the Wilcoxon rank-sum test for comparisons of continuous variables when assumptions for the $t$-test were not met. Pearson's correlation test was used for normally distributed variables; otherwise, Spearman's rank correlation test was applied. Significant determinants identified from the correlation tests were studied in a stepwise multiple regression model. All variables that correlated with the patients' $\mathrm{Hb}$ levels with a $P$-value of $<0.15$ were included in the test model. Variance inflation factor (VIF) calculation was applied to address the issue of collinearity. We performed the analysis with the Statistics Package for Social Science 15.0 software (SPSS Inc., Chicago, IL, USA). A $P$-value of $<0.05$ was considered statistically significant.

\section{Results}

\section{Subject characteristics}

A total of 179 patients undergoing chronic PD consented to participate in the study. After excluding those who did not fulfill the inclusion criteria, 165 patients (49 men [29.7\%] and 116 women [70.3\%]) were enrolled into the study.

All the participants were of Chinese origin. Their ages ranged from 19 to 84 years with a mean (SD) of 50.0 (10.8) years. Among them, 151 patients were on continuous ambulatory PD, whereas 14 were on automated PD. The underlying causes of end-stage renal disease were diabetes mellitus in 21 patients $(12.7 \%)$, chronic glomerulonephritis in $75(45.5 \%)$, hypertension in $15(9 \%)$, obstructive uropathy in $3(1.8 \%)$, gouty nephropathy in $2(1.2 \%)$, tubulointerstitial disease in $2(1.2 \%)$, and unknown in 47 patients $(28.5 \%)$.

\section{Comparison between non-anuric and anuric patients}

Patients were divided into two groups: non-anuric $(n=90)$ and anuric $(n=75)$. The demographic data and clinical characteristics of these two groups are shown in Table 1. Compared with non-anuric patients, anuric patients had longer PD vintage and higher levels of serum alkaline phosphatase and hsCRP. Notably, we found no difference in serum total IS between these two groups and a higher free IS level in non-anuric subjects. Thus, the unbound percentage of IS was higher in non-anuric patients than in anuric patients $(26.3 \% \pm 7.5 \%$ versus $16.8 \% \pm 6.5 \%, P<0.001)$. A significant correlation between serum albumin and total IS was found in anuric subjects, but not in non-anuric subjects $\left(r_{s}=0.263, P=0.023\right.$ and $r_{s}=0.190, P=0.072$, respectively).

\section{Factors influencing anemia in all subjects}

There was no relationship between serum IS (both in total and free forms) and $\mathrm{Hb}$ levels in total study patients $\left(r_{s}=-0.074\right.$, $P=0.348$ for total IS and $r_{s}=0.018, P=0.82$ for free IS $)$. The following clinical variables showed significant associations with $\mathrm{Hb}$ level: ferritin $\left(r_{s}=-0.253, P=0.001\right)$, hsCRP $\left(r_{s}=-0.252, P=0.001\right)$, male gender $\left(r_{s}=0.248, P=0.001\right)$, transferrin saturation $\left(r_{s}=0.332, P<0.001\right)$, and use of ACEI and/or ARB ( $\left.r_{s}=-0.257, P=0.001\right)$.

\section{Factors influencing anemia in non-anuric subjects}

Associations between $\mathrm{Hb}$ levels and other clinical variables are shown in Table 2. There was a moderate correlation between the levels of $\mathrm{Hb}$ and total IS $\left(r_{s}=-0.405, P<0.001\right.$; Figure 1) and weak correlations between the $\mathrm{Hb}$ levels and the following factors: normalized renal creatinine clearance, transferrin saturation, free IS, gender, use of ACEI/ARB, and hsCRP. In the stepwise multiple regression model, two factors were included as predictors for $\mathrm{Hb}$ level: iron saturation and serum total IS (Table 3). These 90 patients were further divided into three tertiles according to their daily urine volumes. We found a strong correlation between the levels of $\mathrm{Hb}$ and total IS in high-volume group $\left(\mathrm{n}=30 ; r_{s}=-0.643\right.$, $P<0.001)$ and a weak correlation in intermediate-volume group $\left(\mathrm{n}=27 ; r_{s}=-0.290, P=0.14\right)$ and low-volume group $\left(\mathrm{n}=33 ; r_{s}=-0.198, P=0.27\right)$.

\section{Factors influencing anemia in anuric subjects}

Using the Spearman's rank correlation test, we found the following clinical variables to be significantly correlated to $\mathrm{Hb}$ levels: ACEI/ARB use, serum albumin, serum ferritin, total serum IS, free IS, serum hsCRP, gender, and transferrin saturation (Table 4). In the stepwise multiple regression model, four factors were predictors for $\mathrm{Hb}$ level: serum ferritin, albumin, transferrin saturation, and ACEI/ARB use. Serum IS was not included as a predictive factor (Table 5).

\section{Discussion}

As a whole, the results showed no correlation between IS and anemia in PD patients. After categorizing subjects into nonanuria and anuric groups, we found a negative correlation between IS and anemia in the non-anuric group, supporting the inhibitory effect of IS on erythropoiesis. The correlation 
Table I Demographic information and clinical characteristics of anuric and non-anuric patients

\begin{tabular}{|c|c|c|c|}
\hline Variables & $\begin{array}{l}\text { Non-anuric patients } \\
(n=90)\end{array}$ & $\begin{array}{l}\text { Anuric patients } \\
(n=75)\end{array}$ & $P$-value \\
\hline Age (years) & $51.0(11.0)$ & $48.7(10.3)$ & 0.17 \\
\hline Male (\%) & $23(25.6)$ & $26(34.7)$ & 0.20 \\
\hline $\operatorname{BSA}\left(m^{2}\right)$ & I.56 (I.44-I.67) & I.58 (I.47-I.72) & 0.27 \\
\hline Causes of renal failure & & & 0.006 \\
\hline Diabetic nephropathy & 12 & 11 & \\
\hline Glomerulonephritis & 51 & 24 & \\
\hline Hypertension & 9 & 6 & \\
\hline Others/unknown & 18 & 34 & \\
\hline PD vintage (months) & $35.0(21.8-53.3)$ & $86.0(51.0-119.0)$ & $<0.001$ \\
\hline \multicolumn{4}{|l|}{ PD modality } \\
\hline CAPD/APD & $78 / 12$ & $73 / 2$ & 0.02 \\
\hline Hypertension (\%) & $55(6 I . I)$ & $43(57.3)$ & 0.62 \\
\hline ACEI/ARB use (\%) & $27(30)$ & $24(32)$ & 0.78 \\
\hline Calcitriol use (\%) & $23(25.6)$ & $28(37.3)$ & 0.10 \\
\hline Hematocrit (\%) & $31.6(3.7)$ & $31.0(4.3)$ & 0.37 \\
\hline Hemoglobin (g/dL) & $10.3(I .1)$ & $10.0(1.7)$ & 0.15 \\
\hline WBC $\left(\times 10^{3} / \mu \mathrm{L}\right)$ & $7.1(5.8-8.4)$ & $7.8(6.4-9.6)$ & 0.019 \\
\hline Platelet $\left(\times 10^{3} / \mu \mathrm{L}\right)$ & $234(20|-3| 2)$ & $256(20 \mathrm{I}-305)$ & 0.43 \\
\hline Albumin (g/dL) & $4.1(0.3)$ & $4.1(0.4)$ & 0.33 \\
\hline AST (U/L) & $18(13-23)$ & $16(14-23)$ & 0.87 \\
\hline ALT (U/L) & $17(13-24)$ & $17(14-23)$ & 0.47 \\
\hline Alk-pase (U/L) & $72(52-106)$ & $90(62-128)$ & 0.004 \\
\hline Transferrin saturation (\%) & $24.6(19.2-33.7)$ & $26.4(18.5-32.1)$ & 0.80 \\
\hline Ferritin $(\mathrm{ng} / \mathrm{mL})$ & $135.5(63.6-252.5)$ & $\mid 86.0(83 .|-4| \mid .0)$ & 0.057 \\
\hline iPTH (pg/mL) & $140(62-308)$ & $214(64-757)$ & 0.073 \\
\hline hsCRP (mg/dL) & $2.0(1.0-5.4)$ & $3.9(1.5-9.4)$ & 0.007 \\
\hline nPCR (g/kg/day) & $1.0(0.9-1.1)$ & $1.0(0.8-1.2)$ & 0.35 \\
\hline nCcr K (L/week) & $9.7(3.9-22.2)$ & $0.0(0.0-0.0)$ & $<0.001$ \\
\hline nCcr P (L/week) & $46.4(10.9)$ & $57.8(10.1)$ & $<0.001$ \\
\hline Weekly renal Kt/V & $0.2(0.1-0.5)$ & $0.0(0.0-0.0)$ & $<0.001$ \\
\hline Weekly peritoneal $\mathrm{Kt} / \mathrm{V}$ & $1.9(0.4)$ & $2.2(0.3)$ & 0.22 \\
\hline Weekly total Kt/V & $2.2(2.0-2.5)$ & $2.2(2.0-2.5)$ & 0.64 \\
\hline Serum total IS (mg/L) & $40.9(28.1-50.3)$ & $41.3(33.8-52.5)$ & 0.52 \\
\hline Serum-free IS (mg/L) & $9.5(7.6-11.9)$ & $7.1(4.6-8.8)$ & $<0.001$ \\
\hline \multicolumn{4}{|l|}{ ESA use } \\
\hline EPO- $\beta /$ darbepoetin- $\alpha /$ none & $72 / 14 / 4$ & $60 / 9 / 6$ & 0.44 \\
\hline ESA dose $\left(10^{3} \mathrm{U} / \text { month }\right)^{\mathrm{a}}$ & $20(14-20)$ & $20(20-20)$ & 0.37 \\
\hline ESA dose $/ \mathrm{BW}(\mathrm{U} / \mathrm{kg} / \mathrm{month})$ & $328(237-393)$ & $329(24 I-385)$ & 0.84 \\
\hline
\end{tabular}

Notes: Given are the means (standard deviation) or medians with interquartile ranges in parentheses, where appropriate, or number of patients with percentages in parentheses. Fisher's exact test, Student's t-test, or Wilcoxon rank-sum test is used, where appropriate. To convert ferritin from ng/mL to pmol/L, we multiplied by 2.247 . To convert aluminum from $\mu \mathrm{g} / \mathrm{L}$ to $\mu \mathrm{mol} / \mathrm{L}$, we multiplied by $0.037 \mathrm{I}$. To convert indoxyl sulfate from $\mathrm{mg} / \mathrm{L}$ to $\mu \mathrm{mol} / \mathrm{L}$, we multiplied by 4.69 . ${ }^{\mathrm{E}} \mathrm{ESA}$ dose is calculated as a monthly dose of recombinant human erythropoietin- $\beta$ or its equivalent ( I $\mu \mathrm{g}$ darbepoetin $=200 \mathrm{U}$ recombinant human erythropoietin- $\beta$ ).

Abbreviations: ACEl, angiotensin-converting enzyme inhibitor; Alk-pase, alkaline phosphatase; ALT, alanine aminotransferase; APD, automated peritoneal dialysis; ARB, angiotensin II receptor blocker; AST, aspartate aminotransferase; BSA, body surface area; CAPD, continuous ambulatory peritoneal dialysis; EPO- $\beta$, recombinant human erythropoietin- $\beta$; ESA, erythropoiesis-stimulating agents; hsCRP, high-sensitivity C-reactive protein; iPTH, intact parathyroid hormone; IS, indoxyl sulfate; Kt/V, urea amount cleared from plasma divided by distribution volume; $\mathrm{nCcr} \mathrm{K}$, normalized renal creatinine clearance; $\mathrm{nCcr}$ P, normalized peritoneal creatinine clearance; $\mathrm{nPCR}$, normalized protein catabolic rate; PD, peritoneal dialysis; WBC, white blood cell.

was, however, absent in the anuric group. When compared with non-anuric subjects, anuric subjects tended to have better protein binding of IS and a higher, though trivial, serum CRP level. Nevertheless, there was no difference in serum total IS levels between these two groups.

IS has long been considered to play an important role in CKD-related anemia. Several in vitro studies have clearly demonstrated the potential inhibitory effect of IS on erythropoiesis. One study has shown a direct dose-dependent suppressive function of IS on erythroid colony formation at concentrations in the range found in uremic patients. ${ }^{9}$ In addition, a research in erythropoietin-producing cells revealed a suppressed erythropoietin mRNA expression by IS at concentrations below cytotoxic ranges. ${ }^{10}$ Furthermore, IS was 
Table 2 Spearman's rank correlations of baseline clinical characteristics with hemoglobin levels in non-anuric peritoneal dialysis subjects

\begin{tabular}{lll}
\hline & Hemoglobin & \\
\cline { 2 - 3 } & $\boldsymbol{r}_{s}$-value & $\boldsymbol{P}$-value \\
\hline Age & 0.05 & 0.63 \\
Male gender & 0.25 & 0.020 \\
PD vintage & -0.18 & 0.095 \\
ACEI/ARB usage & -0.21 & 0.048 \\
Albumin & 0.02 & 0.83 \\
Alkaline phosphatase & -0.16 & 0.14 \\
Intact parathyroid hormone & -0.15 & 0.17 \\
Transferrin saturation & 0.38 & $<0.001$ \\
Ferritin & -0.14 & 0.20 \\
hsCRP & -0.20 & 0.068 \\
nPCR & 0.06 & 0.59 \\
nCcr P & -0.11 & 0.29 \\
nCcr K & 0.38 & $<0.00$ I \\
Total IS & $-0.4 I$ & $<0.001$ \\
Free IS & -0.30 & 0.005 \\
\hline A & &
\end{tabular}

Abbreviations: $\mathrm{ACEl}$, angiotensin-converting enzyme inhibitor; $\mathrm{ARB}$, angiotensin II receptor blocker; hsCRP, high-sensitivity C-reactive protein; $\mathrm{nCcr} \mathrm{K}$, normalized renal creatinine clearance; IS, indoxyl sulfate; $\mathrm{nCcr} P$, normalized peritoneal creatinine clearance; $\mathrm{nPCR}$, normalized protein catabolic rate; PD, peritoneal dialysis.

shown to stimulate suicidal death of red cells (eryptosis) via enhanced transcellular calcium influx. ${ }^{11}$ Clinically, in patients with type 2 diabetes whose serum creatinine levels were $\leq 1.5 \mathrm{mg} / \mathrm{dL}$, serum IS level was associated with the severity of anemia. ${ }^{12}$ Still, studies on the relationship between IS and anemia in the advanced CKD patients are limited. Our results provide an evidence that IS correlates to $\mathrm{Hb}$ in nonauric PD patients, although not in anuric ones. Results from

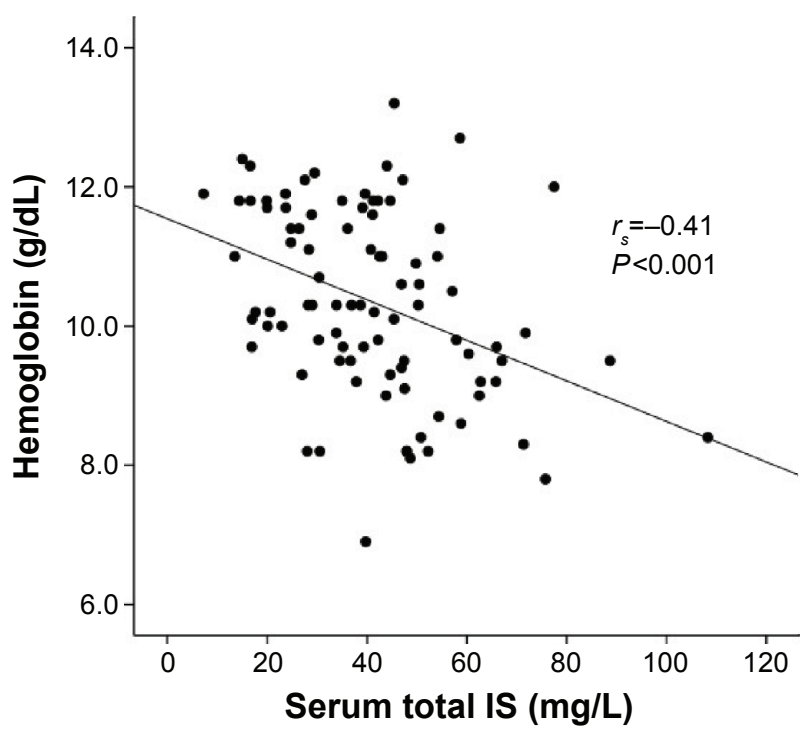

Figure I Correlation between hemoglobin and serum IS levels in non-anuric peritoneal dialysis patients.

Abbreviation: IS, indoxyl sulfate.
Table 3 Multivariate predictors of hemoglobin in non-anuric subjects undergoing peritoneal dialysis

\begin{tabular}{llllll}
\hline & $\mathbf{B}$ & $\mathbf{S E}$ & $\mathbf{9 5 \%} \mathbf{C l}$ of $\mathbf{B}$ & $\boldsymbol{\beta}$ & $\boldsymbol{P}$-value \\
\hline Constant & I5.I4I & 0.983 & $\mathrm{I} 3.186$ to 17.095 & & $<0.00 \mathrm{I}$ \\
Log iron & $2.52 \mathrm{I}$ & 0.718 & $\mathrm{I} .093$ to 3.948 & 0.332 & $0.00 \mathrm{I}$ \\
saturation & & & & & \\
Log total IS & -2.093 & 0.617 & -3.320 to -0.866 & -0.320 & $0.00 \mathrm{I}$ \\
\hline
\end{tabular}

Notes: $R=0.507, R^{2}=0.257$, adjusted $R^{2}=0.24$. Excluded factors: albumin, highsensitivity C-reactive protein, gender, angiotensin-converting enzyme inhibitor/ angiotensin II receptor blocker use, ferritin, residual renal creatinine clearance.

Abbreviations: $\beta$, standardized regression coefficient; $B$, unstandardized regression coefficient; $\mathrm{Cl}$, confidence interval; $\mathrm{IS}$, indoxyl sulfate; $\mathrm{SE}$, standard error of the estimate.

these clinical investigations suggest that the effect of IS on anemia may exist from early to advanced stages of CKD.

Efforts have been made to reduce the body's IS burden. Daily hemodialysis or addition of absorbents to the dialysate during hemodialysis offers patients a viable option to decrease IS load. ${ }^{19,20}$ Oral absorbents, typically activated charcoal and AST-120, have been advocated to reduce gastrointestinal absorption of indole and IS accumulation in the body. Although potentially effective in reducing IS burden, the administration of AST-120 in CKD stages III-V patients yielded inconsistent results in the improvement of anemia. In patients with moderate CKD (serum creatinine $1.3-2.0 \mathrm{mg} / \mathrm{dL}$ ), no improvement of anemia was found after 2-year administration of AST-120. ${ }^{13}$ On the contrary, the use of oral AST-120 in stage V CKD patients was demonstrated to potentiate the effect of ESA. ${ }^{14}$ Taking these results together, maximal effort to reduce IS burden in high-risk

Table 4 Spearman's rank correlations of baseline clinical characteristics with hemoglobin levels in anuric peritoneal dialysis subjects

\begin{tabular}{lll}
\hline & \multicolumn{2}{l}{ Hemoglobin } \\
\cline { 2 - 3 } & $\boldsymbol{r}_{s}$-value & P-value \\
\hline Age & -0.131 & 0.261 \\
Male gender & 0.273 & 0.018 \\
PD vintage & -0.18 & 0.095 \\
ACEI/ARB usage & -0.317 & 0.006 \\
Albumin & 0.326 & 0.004 \\
Alkaline phosphatase & -0.069 & 0.558 \\
Intact parathyroid hormone & 0.028 & 0.813 \\
Transferrin saturation & 0.272 & 0.018 \\
Ferritin & -0.370 & 0.001 \\
hsCRP & -0.264 & 0.002 \\
nPCR & -0.072 & 0.541 \\
nCcr P & -0.116 & 0.323 \\
nCcr K & 0.084 & 0.475 \\
Total IS & 0.365 & 0.001 \\
Free IS & 0.286 & 0.014 \\
\hline
\end{tabular}

Abbreviations: ACEI, angiotensin-converting enzyme inhibitor; ARB, angiotensin II receptor blocker; hsCRP, high-sensitivity C-reactive protein; IS, indoxyl sulfate; $\mathrm{nCcrK}$, normalized renal creatinine clearance; $\mathrm{nCcr} P$, normalized peritoneal creatinine clearance; $\mathrm{nPCR}$, normalized protein catabolic rate; PD, peritoneal dialysis. 
Table 5 Multivariate predictors of hemoglobin in anuric subjects undergoing peritoneal dialysis

\begin{tabular}{llllll}
\hline & B & SE & 95\% Cl of B & $\beta$ & P-value \\
\hline Constant & 9.216 & 2.213 & 4.803 to 13.628 & & $<0.001$ \\
Log ferritin & -1.436 & 0.344 & -2.121 to -0.750 & -0.463 & $<0.00$ I \\
Albumin & 1.451 & 0.438 & 0.577 to 2.325 & 0.317 & 0.001 \\
Log iron & 2.608 & 0.987 & 0.638 to 4.577 & 0.286 & 0.010 \\
saturation & & & & & \\
ACEI/ARB use & -0.720 & 0.346 & -1.410 to -0.029 & -0.204 & 0.041 \\
\hline
\end{tabular}

Notes: $R=0.604, R^{2}=0.365$, adjusted $R^{2}=0.329$. Excluded factors: total IS, highsensitivity $C$-reactive protein, and gender.

Abbreviations: $\beta$, standardized regression coefficient; ACEI, angiotensinconverting enzyme inhibitor; $A R B$, angiotensin II receptor blocker; $B$, unstandardized regression coefficient; $\mathrm{Cl}$, confidence interval; IS, indoxyl sulfate; SE, standard error of the estimate.

patients is demanded to confirm the role of IS in CKDassociated anemia.

Notably, we observed higher protein binding of IS in anuric patients than in non-anuric ones. This finding is consistent with the study of Eloot et al that showed a trend of decreasing unbound percentage of IS in CKD subjects with the progression of chronic renal failure. ${ }^{15} \mathrm{~A}$ crude estimation from their data reveals the unbound percentage of IS is $21.3 \%$ for stage II, $11.5 \%$ for stage III, $8.7 \%$ for stage IV, and $6.5 \%$ for stage $\mathrm{V}$ CKD. However, two previous works in PD patients showed no difference in unbound percentage of IS between PD patients with and without residual kidney function. ${ }^{16,17}$ Thus, studies to confirm the difference of protein binding between anuric and non-anuric groups and to investigate the underlying mechanism are required. Nevertheless, derangement in acid-base status seems not to be the cause because one study on high-affinity binding constant for IS has clearly demonstrated no significant influence by $\mathrm{pH} .{ }^{21}$ As IS may bind to albumin better in anuric patients, causing a positive correlation between IS and $\mathrm{Hb}$ levels in simple regression, statistical methods such as VIF are needed to address the problem of collinearity.

In our study, anuric subjects had higher serum level of C-reactive protein, a biomarker for acute inflammation process that is considered to play a vital role in CKD-associated malnutrition and anemia. ${ }^{22}$ In addition, our anuric patients tended to have renal hyperparathyroidism, evidenced by the elevation of serum alkaline phosphatase and borderline increase in iPTH. Oversecretion of parathyroid hormone aggravates anemia via suppression of erythroid progenitor cell, shortening of erythrocyte life span, reduction of endogenous erythropoietin synthesis, and bone marrow fibrosis. ${ }^{23}$ Furthermore, a variety of uremic retention solutes, such as spermine and furancarboxylic acid, have also been shown to inhibit erythropoiesis. ${ }^{24,25}$ It is legitimate to hypothesize that these inhibitors of erythropoiesis accumulate more in anuric patients than in non-anuric patients. Therefore, the altered protein binding of IS, together with enhanced inflammation, oversecretion of parathyroid hormone, and increased accumulation of other erythropoiesis-inhibiting retention solutes, may partly explain the confounding effect of anuria on the relation between IS and anemia.

There are some limitations to this study. First, as this study is observational and cross-sectional, to deduce a causal relationship from the results is arguable. More longitudinal observations or clinical trials to evaluate the outcome of anemia after reducing serum IS are required to confirm the causality. Second, because the dose of administered ESA in the study was dynamically adjusted to meet governmental guidelines of that time, this modification may yield results not reflective of the true relationship. Third, we found no difference in serum IS levels between non-anuric and anuric patients. As IS arises from the breakdown of tryptophan, nutrient intake may affect its serum levels in CKD patients. Yet, we did not collect patients' dietary data to perform an analysis.

In conclusion, this observational study demonstrated an association between serum IS and the severity of anemia in non-anuric PD patients, but not in anuric subjects, indicating anuria itself may be a confounding factor in relationship between IS and anemia. Further studies are required to elucidate the underlying cause and validate the effect of IS reduction in improving anemia in dialysis patients.

\section{Acknowledgments}

We thank Conmed Pharmaceutical \& Bio-medical Corporation and Prevision Medical Corporation for their financial support in detecting the levels of serum indoxyl sulfate. The authors are indebted to Ms Shu-Man Weng for her assistance in sample and data collection. In addition, we wish to thank Dr Jen Liang Su for his help in translating the original Japanese article and Dr Ping-Chin Lai in editing figures. Parts of the results were presented as a poster at the World Congress of Nephrology (Vancouver, 2011).

\section{Disclosure}

The authors report no conflicts of interest in this work.

\section{References}

1. Foley RN, Parfrey PS, Harnett JD, Kent GM, Murray DC, Barre PE. The impact of anemia on cardiomyopathy, morbidity, and mortality in end-stage renal disease. Am J Kidney Dis. 1996;28(1):53-61.

2. Nangaku M, Eckardt KU. Pathogenesis of renal anemia. Semin Nephrol. 2006;26(4):261-268. 
3. Patel NM, Gutierrez OM, Andress DL, Coyne DW, Levin A, Wolf M. Vitamin D deficiency and anemia in early chronic kidney disease. Kidney Int. 2010;77(8):715-720.

4. Singh AK, Szczech L, Tang KL, et al; CHOIR Investigators. Correction of anemia with epoetin alfa in chronic kidney disease. $N$ Engl J Med. 2006;355(20):2085-2098.

5. Drueke TB, Locatelli F, Clyne N, et al. Normalization of hemoglobin level in patients with chronic kidney disease and anemia. N Engl J Med. 2006;355(20):2071-2084.

6. Pfeffer MA, Burdmann EA, Chen CY, et al; TREAT Investigators. A trial of darbepoetin alfa in type 2 diabetes and chronic kidney disease. N Engl J Med. 2009;361(21):2019-2032.

7. Opatrny K Jr, Reischig T, Vienken J, et al. Does treatment modality have an impact on anemia in patients with chronic renal failure? Effect of low- and high-flux biocompatible dialysis. Artif Organs. 2002;26(2): 181-188.

8. Ward RA, Schmidt B, Hullin J, Hillebrand GF, Samtleben W. A comparison of on-line hemodiafiltration and high-flux hemodialysis: a prospective clinical study. J Am Soc Nephrol. 2000;11(12):2344-2350.

9. Kawashima Y. [Study on the uremic protein binding inhibitors as uremic toxin: toxic effect on erythroid colony formation, lymphocyte blast formation and renal function]. Nihon Jinzo Gakkai Shi. 1989;31(11): 1151-1161. Japanese.

10. Chiang CK, Tanaka T, Inagi R, Fujita T, Nangaku M. Indoxyl sulfate, a representative uremic toxin, suppresses erythropoietin production in a HIF-dependent manner. Lab Invest. 2011;91(11):1564-1571.

11. Ahmed MS, Abed M, Voelkl J, Lang F. Triggering of suicidal erythrocyte death by uremic toxin indoxyl sulfate. BMC Nephrol. 2013; $14: 244$.

12. Atoh K, Itoh H, Haneda M. Serum indoxyl sulfate levels in patients with diabetic nephropathy: relation to renal function. Diabetes Res Clin Pract. 2009;83(2):220-226.

13. Shibahara H, Shibahara N. Cardiorenal protective effect of the oral uremic toxin absorbent AST-120 in chronic heart disease patients with moderate CKD. J Nephrol. 2010;23(5):535-540.

14. Wu IW, Hsu KH, Sun CY, Tsai CJ, Wu MS, Lee CC. Oral adsorbent AST-120 potentiates the effect of erythropoietin-stimulating agents on stage 5 chronic kidney disease patients: a randomized crossover study. Nephrol Dial Transplant. 2014;29(9):1719-1727.
15. Eloot S, Schepers E, Barreto DV, et al. Estimated glomerular filtration rate is a poor predictor of concentration for a broad range of uremic toxins. Clin J Am Soc Nephrol. 2011;6(6):1266-1273.

16. Pham NM, Recht NS, Hostetter TH, Meyer TW. Removal of the protein-bound solutes indican and p-cresol sulfate by peritoneal dialysis. Clin J Am Soc Nephrol. 2008;3(1):85-90.

17. Lee CT, Kuo CC, Chen YM, et al. Factors associated with blood concentrations of indoxyl sulfate and p-cresol in patients undergoing peritoneal dialysis. Perit Dial Int. 2010;30(4):456-463.

18. Viaene L, Meijers BK, Vanrenterghem Y, Evenepoel P. Serum concentrations of p-cresyl sulfate and indoxyl sulfate, but not inflammatory markers, increase in incident peritoneal dialysis patients in parallel with loss of residual renal function. Perit Dial Int. 2015; 35(4):492

19. Fagugli RM, De Smet R, Buoncristiani U, Lameire N, Vanholder R. Behavior of non-protein-bound and protein-bound uremic solutes during daily hemodialysis. Am J Kidney Dis. 2002;40(2):339-347.

20. Meyer TW, Peattie JW, Miller JD, et al. Increasing the clearance of protein-bound solutes by addition of a sorbent to the dialysate. $J \mathrm{Am}$ Soc Nephrol. 2007;18(3):868-874.

21. Sakai T, Yamasaki K, Sako T, Kragh-Hansen U, Suenaga A, Otagiri M. Interaction mechanism between indoxyl sulfate, a typical uremic toxin bound to site II, and ligands bound to site I of human serum albumin. Pharm Res. 2001;18(4):520-524.

22. Lowrie EG. Acute-phase inflammatory process contributes to malnutrition, anemia, and possibly other abnormalities in dialysis patients. Am J Kidney Dis. 1998;32(6 Suppl 4):S105-S112.

23. Brancaccio D, Cozzolino M, Gallieni M. Hyperparathyroidism and anemia in uremic subjects: a combined therapeutic approach. J Am Soc Nephrol. 2004;15 Supp1 1:S21-S24.

24. Radtke HW, Rege AB, LaMarche MB, et al. Identification of spermine as an inhibitor of erythropoiesis in patients with chronic renal failure. J Clin Invest. 1981;67(6):1623-1629.

25. Niwa T, Yazawa T, Kodama T, Uehara Y, Maeda K, Yamada K. Efficient removal of albumin-bound furancarboxylic acid, an inhibitor of erythropoiesis, by continuous ambulatory peritoneal dialysis. Nephron. 1990;56(3):241-245.
Therapeutics and Clinical Risk Management

\section{Publish your work in this journal}

Therapeutics and Clinical Risk Management is an international, peerreviewed journal of clinical therapeutics and risk management, focusing on concise rapid reporting of clinical studies in all therapeutic areas outcomes, safety, and programs for the effective, safe, and sustained use of medicines. This journal is indexed on PubMed Central, CAS,

\section{Dovepress}

EMBase, Scopus and the Elsevier Bibliographic databases. The manuscript management system is completely online and includes a very quick and fair peer-review system, which is all easy to use. Visit http://www.dovepress.com/testimonials.php to read real quotes from published authors. 